\title{
The Impact of Narrative Mode on the Theme and the Level of Positive Processing of Psychobiography
}

\author{
Suping Cheng*, Yuqiu Chen \\ School of Education, Hangzhou Normal University, Hangzhou, China \\ Email: 20040080@hznu.edu.cn
}

How to cite this paper: Cheng, S.P. and Chen, Y.Q. (2020) The Impact of Narrative Mode on the Theme and the Level of Positive Processing of Psychobiography. Open Access Library Journal, 7: e6884. https://doi.org/10.4236/oalib.1106884

Received: October 9, 2020

Accepted: October 26, 2020

Published: October 29, 2020

Copyright $\odot 2020$ by author(s) and Open Access Library Inc.

This work is licensed under the Creative Commons Attribution International License (CC BY 4.0).

http://creativecommons.org/licenses/by/4.0/

\begin{abstract}
This study examined the effects of different narrative modes (writing and speaking) on the theme (Agency and Communion) and the level of positive processing through a group counseling based on psychobiographical therapy. A qualitative study approach was used to encode and analyze the life stories collected by group counseling. Results: The number of Communion in the speaking group was higher than that in the writing group, and the positive processing level of the writing group was higher than that of the speaking group. Conclusion: Different narrative modes have different effects on the theme and the level of positive processing.
\end{abstract}

\section{Subject Areas}

Education

\section{Keywords}

Speaking, Writing, Psychological Biography, Theme, Positive Processing

\section{Introduction}

Speaking and writing are two important narrative modes from different processing channels of individuals, constructing one's coherent life story in these two modes has an important impact on the individual's perception of the present (Pennebaker \& Graybeal, 2001) [1] and expectation of the future (Cox \& Mcadams, 2014) [2]. Moreover, researchers have found that the content of life story is different under different narrative modes (McCoy \& Dunlop, 2016 [3]; Grysman \& Denney, 2017 [4]). Thus, it can be speculated that different narrative Cheng Suping and Chen Yuqiu contributed equally. 
modes may have a direct impact on the content of life story, but these studies were conducted in the laboratory, not in actual clinical interventions. Therefore, it remains to be further studied whether different narrative styles will affect the content of life stories in clinical interventions.

Psychobiographical therapy is a form of psychotherapy, and refers to the process in which the client, with the help of a counselor, speak, listen to and write his or her own complete life story, as well as read the biographies of prominent or iconic figures, to make positive changes in the client and transform his or her life story with obstacles into a good life story (Zheng Jinghong, He Chenglin, 2015) [5]. It consists of four stages: 1) speaking a story; 2) listening to a story; 3) reading a story; 4) writing a story. Both the story-speaking in the first stage and the story-writing in the last stage are the client constructs his own life story. With the help of these two stages, researchers can collect the client's life story text. Therefore, psychobiographical therapy can be used not only as psychotherapy, but also as a medium for collecting life stories.

At present, the coding of life stories is mainly from three aspects: motivational and affective themes, autobiographical reasoning, and structural aspects (McLean et al., 2019) [6]. Among them, the agency and communion themes that is most closely related to individual life satisfaction, happiness, emotional maturity and physical health (Adler \& Jonathan, 2012) [7]. The agency is an individual's ideals of strength, power, expansion, mastery, control, dominance, autonomy, separation, and independence, focus primarily on self; the communion emphasizes the intimate, warm and caring relationship between individuals and others (Dan, 2001) [8]. However, in the comparative study of speaking and writing, the way of write is more conducive to improving your physical symptoms and health (Lyubomirsky et al., 2006) [9]. Therefore, it can be speculated that the level of agency and communion may be higher under the writing mode. But there are studies that contradict this assumption (McCoy \& Dunlop, 2016) [3]. Therefore, it remains to be confirmed whether different narrative modes will affect the level of agency and communion.

Autobiographical reasoning in the life story refers to an ever-evolving, interpretive process of connecting past events to self (Habermas \& Bluck, 2000) [10]. Later research divided it into positive processing and differentiated processing (Lilgendahl \& Mcadams, 2011) [11]. Positive processing refers to the positive degree of individuals to explain past events. Compared with differentiated processing, it is more conducive to distinguish individuals' differences in processing styles and better predict physical and mental health (Cox \& Mcadams, 2014) [2]. The result of a meta-analysis of autobiographical reasoning show that both the speaking and the writing of past events translate the inner emotions and images into a highly structured language, and this process can change the organization and interpretation of past events of individuals (Frattaroli \& Joanne, 2006) [12]. This means that both speaking and writing can affect the processing, but it is still not clear which has the greater impact.

This study is based on psychobiographical therapy to explore whether differ- 
ent narrative modes will affect the agency, communion and positive processing level of life stories in the actual intervention process.

\section{Method}

\subsection{Participants}

Through voluntary registration and interview screening, 24 college students (12 male students and 12 female students) were selected. The age ranges from 18 to 20 years old $(M=19, S D=0.417)$. They were randomly divided into a writing group and a speaking group, with 12 people in each group. Our study's sample size was consistent with recommendations from the American Balint Society describing best practices for facilitated small-group work involving health care professionals with shared experiences(Roberts, 2012) [13].

\subsection{Procedure}

\subsubsection{Intervention Preparation Stage}

The formation of the group counseling program mainly refers to the four basic steps of psychobiographical therapy: speaking a story, listening to a story, reading a story and writing a story. In both the story-speaking and story-writing stages, participants were asked to describe 10 life story segments within $30 \mathrm{mi}-$ nutes, topics include life-story high point, low point, turning points, earliest memories, deepest memories, plans, parent-child relationships, relationships with other family members, significant others in life and perceptions of one's own appearance. After the program was determined, three psychology professors were invited to collect expert opinions, and the results showed that the program had good content validity, $\mathrm{I}-\mathrm{CVI}=1, \mathrm{~S}-\mathrm{CVI}=1$. The group counseling program is shown in Table 1. In order to ensure the effectiveness of the program, the group counseling leaders were trained in psychobiographical therapy and have many experiences in the group counseling and case counseling.

\subsubsection{Intervention Implementation Stage}

Participants in both the speaking group and the writing group received group counseling intervention once a week for 1.5 hours each time for a total of 7 times. During this period, the life stories of the speaking group and the writing group in stages speaking a story (story I) and writing a story (story II) were collected. The speaking group uses recorders to record the story of life. During the intervention, the consistency of independent variables such as leader and time was controlled.

\subsection{Coding of Life Story}

The paper material of the writing group is recovered, and the recording of the speaking group is converted into text. The three raters were trained and studied on the coding standard of the theme and the positive processing level, and then scored independently. Coding for the theme is based on coding standards compiled by Dan (2001) [8]. He divided the theme into Agency and Communion. The 
Table 1. Program of group counseling.

\begin{tabular}{|c|c|c|}
\hline Topic & Objectives & $\begin{array}{c}\text { Contents (There is a sharing } \\
\text { after each session) }\end{array}$ \\
\hline 1) the beginning & $\begin{array}{l}\text { Get to know each other and } \\
\text { form groups }\end{array}$ & $\begin{array}{l}\text { Make name card, find their position, } \\
\text { I am an engraver, find a partner }\end{array}$ \\
\hline 2) speaking a story & $\begin{array}{l}\text { Assist the members to construct } \\
\text { the life story for the first time }\end{array}$ & $\begin{array}{l}\text { Pat exercise (warm-up), build their } \\
\text { own life story (speaking group: } \\
\text { speaking life story; Writing group: } \\
\text { writing life stories) }\end{array}$ \\
\hline $\begin{array}{l}\text { 3) listening to a } \\
\text { story }\end{array}$ & $\begin{array}{l}\text { To assist members in viewing their } \\
\text { own life stories from the perspective } \\
\text { of a third party }\end{array}$ & $\begin{array}{c}\text { A dollar and fifty cents (warm-up), } \\
\text { listen to your partner's } \\
\text { own life story }\end{array}$ \\
\hline 4) reading a story & $\begin{array}{l}\text { Members read biographies of } \\
\text { prominent people who are } \\
\text { similar to or interested in them }\end{array}$ & $\begin{array}{l}\text { Compare sizes (warm-up) and read } \\
\text { biographies of famous people }\end{array}$ \\
\hline 5) writing a story & $\begin{array}{l}\text { Assist the members to } \\
\text { reconstruct the life story }\end{array}$ & $\begin{array}{l}\text { The wind blows (warm-up) and } \\
\text { reconstructs his life story (speaking } \\
\text { group: retelling the life story; Writing } \\
\text { group: rewriting the life story) }\end{array}$ \\
\hline $\begin{array}{l}\text { 6) Contrastive } \\
\text { reflection stage }\end{array}$ & $\begin{array}{l}\text { Assist members to compare two } \\
\text { life stories and discover positive } \\
\text { changes and reinforce them }\end{array}$ & $\begin{array}{l}\text { Untie thousands of knots } \\
\text { (warm-up), my change }\end{array}$ \\
\hline 7) the end stage & $\begin{array}{l}\text { Organize and review the whole } \\
\text { process of group activities }\end{array}$ & $\begin{array}{l}\text { Back when the road, the advantages of } \\
\text { the bombing, thank you for listening } \\
\text { to me, the end of the group }\end{array}$ \\
\hline
\end{tabular}

agency includes self-mastery (SM), status/victory (SV), achievement/responsibility (AR), empowerment (EM); The communion include love/friendship (LF), dialogue (DG), caring/help (CH) and unity/togetherness (UT). A single life fragment may contain more than one agency or communion, regardless of the number, with a score of 1 for any sign of presence.

The coding of positive processing is based on the standard compiled by Lilgendahl (2011) [11]. Firstly, the valence of the event should be coded on a 1 to 5 scale, and the higher the score, the more positive the event. Secondly, the participants' positive degree of event interpretation was rated on a 1 to 5 scale, that is, the positive processing level, the higher the score, the more positive the interpretation. Finally, the average of event valance and positive processing level are calculated.

\section{Result}

\subsection{Comparison of Theme Differences in Two Stages and Two Groups}

Paired-samples t-test was performed on the two-stage life story themes of the speaking group and writing group. The results showed that there were before 
and after differences in the number of the two sub-themes in the agency of the speaking group: "Self-mastery" significantly increased $(t=-3.173, p<0.01)$, "Status/victory" decreased significantly $(t=3.767, \mathrm{p}<0.01)$. There was a difference in the number of three sub-themes in the writing group: "Self-mastery" significantly increased $(t=-3.380, p<0.01)$, "status/victory" significantly decreased $(\mathrm{t}=4.000, \mathrm{p}<0.01)$, and "dialogue" significantly increased $(\mathrm{t}=-3.000, \mathrm{p}$ $<0.05)$.

Theme differences between the two groups were compared by independent-samples t-test. In life story I, there is a difference in the communion between the speaking group and the writing group: On the sub-theme of "love/friendship", the speaking group was significantly lower than the writing group $(t=-2.154, p<0.05)$; In terms of "dialogue" $(t=3.118, p<0.01)$, "unity/togetherness" ( $t=2.737, \mathrm{p}<0.05)$ and "total score of communion" $(\mathrm{t}=2.974$, $\mathrm{p}<0.01$ ), the speaking group was significantly higher than the writing group. In life story II, "unity/togetherness" $(\mathrm{t}=3.344, \mathrm{p}<0.01)$ and the "total score of communion" ( $t=3.527, \mathrm{p}<0.01)$, are all speaking group is significantly higher than writing group.

\subsection{Comparison of Positive Processing Level Differences in Two Stages and Two Groups}

Covariance analysis was used to analyze the difference of positive processing level between the two groups and within the group based on controlling event valence. In the intragroup comparison, the speaking group had a significantly higher positive level of processing in one's life story II than I ( $\mathrm{F}=17.824, \mathrm{p}<$ 0.001); The average score of positive processing level of life story II in the writing group was higher than that of life story I, but it was not significant. On the whole, the positive processing level of life story II was significantly higher than that of life story $\mathrm{I}(\mathrm{F}=12.270, \mathrm{P}<0.01)$. In intergroup comparison, In life story $\mathrm{I}$, the positive processing level of writing group was significantly higher than that of the speaking group $(\mathrm{F}=9.694, \mathrm{P}<0.01)$; In life story II, there was no significant difference in positive processing between the two groups. On the whole, the positive processing level of the writing group was higher than that of the speaking group $(\mathrm{F}=5.790, \mathrm{P}<0.05)$.

\section{Discussion}

\subsection{Analysis of the Differences of Themes within and between Two-Stage Life Story Groups}

In the comparison of theme differences between the speaking group and the writing group, the theme of self-mastery in life story II is higher than that in life story I, which is consistent with the viewpoint described in narrative identity theory. The theory of narrative identity holds that the construction of the life story can provide self with a sense of purpose, meaning and unity (McAdams, 2001 [14]; McAdams, 1996 [15]). Through the construction of life stories, indi- 
viduals will continue to understand the goals and meaning of life at all stages, and the plot and content will become more and more reasonable, to gain a sense of mastery (Klein \& Boals, 2001) [16]. It can also be seen from Table 2 and Table 3 that the status/victory sub-theme of life story II is lower than that of life story I in both the speaking group and the writing group. This may be due to a deeper understanding of the meaning of own life story, the individual's sense of self-control increases, while the need to affirm oneself through others' identity and external status decrease.

In the comparison of theme differences between the speaking group and the writing group, the number of communion in the two-stage life stories of the speaking group was higher than that of the writing group. This result is inconsistent with the research hypothesis. Compared with the previous study, the speaking group in this study replaced the recorder with the listener, which is closer to the reality and is conducive to the clinical application of the research

Table 2. Comparison of Themes differences.

\begin{tabular}{|c|c|c|c|c|c|c|c|c|}
\hline \multirow[b]{2}{*}{ Theme } & \multicolumn{2}{|c|}{ Peaking group } & \multicolumn{2}{|c|}{ Writing group } & \multirow{2}{*}{$\begin{array}{c}\text { (1)(2) } \\
t\end{array}$} & \multirow{2}{*}{$\begin{array}{c}\text { (3)(4) } \\
t\end{array}$} & \multirow{2}{*}{$\begin{array}{c}\text { (1)(3) } \\
t\end{array}$} & \multirow{2}{*}{$\begin{array}{c}\text { (2)(4) } \\
t\end{array}$} \\
\hline & $\begin{array}{c}\text { Life story I } \\
(M \pm S D) \\
\text { (1) }\end{array}$ & $\begin{array}{c}\text { Life story II } \\
(M \pm S D) \\
\text { (2) }\end{array}$ & $\begin{array}{c}\text { Life story I } \\
(M \pm S D) \\
\text { (3) }\end{array}$ & $\begin{array}{c}\text { Life story II } \\
(M \pm S D) \\
\text { (4) }\end{array}$ & & & & \\
\hline SM & $5.166 \pm 1.992$ & $7.250 \pm 1.712$ & $3.917 \pm 1.782$ & $6.917 \pm 2.151$ & $-3.173^{\star *}$ & $-3.380^{\star \star}$ & 1.620 & 0.420 \\
\hline SV & $1.333 \pm 1.231$ & $0.250 \pm 0.626$ & $1.583 \pm 1.443$ & $0.250 \pm 0.622$ & $3.767^{* *}$ & $4.000^{* *}$ & -0.457 & -0.000 \\
\hline $\mathrm{AR}$ & $0.250 \pm 0.452$ & $0.250 \pm 0.452$ & $0.250 \pm 0.622$ & $0.417 \pm 0.515$ & 0.000 & -0.804 & -0.000 & -0.842 \\
\hline $\mathrm{EM}$ & $1.416 \pm 0.763$ & $2.00 \pm 1.045$ & $1.167 \pm 1.115$ & $1.250 \pm 0.965$ & -1.865 & -0.290 & 0.633 & 1.827 \\
\hline LF & $0.583 \pm 0.900$ & $0.833 \pm 0.577$ & $1.500 \pm 0.168$ & $0.917 \pm 1.084$ & -1.000 & 1.400 & $-2.154^{\star}$ & -0.235 \\
\hline DG & $2.333 \pm 2.229$ & $1.833 \pm 1.193$ & $0.250 \pm 0.622$ & $1.000 \pm 1.044$ & 0.804 & $-3.000^{*}$ & $3.118^{\star *}$ & 1.820 \\
\hline $\mathrm{CH}$ & $0.333 \pm 0.779$ & $0.250 \pm 0.622$ & $0.000 \pm 0.000$ & $0.083 \pm 0.289$ & 0.266 & -1.000 & 1.483 & 0.842 \\
\hline UT & $2.166 \pm 1.193$ & $1.417 \pm 0.669$ & $0.833 \pm 1.193$ & $0.500 \pm 0.674$ & 1.827 & 0.886 & $2.737^{\star}$ & $3.344^{* *}$ \\
\hline Agency & $8.167 \pm 2.657$ & $9.750 \pm 2.261$ & $6.917 \pm 2.392$ & $8.833 \pm 2.552$ & -1.811 & -2.091 & 1.211 & 0.931 \\
\hline communion & $5.417 \pm 2.575$ & $4.333 \pm 1.497$ & $2.583 \pm 2.065$ & $2.500 \pm 1.000$ & 1.817 & 0.158 & $2.974^{\star *}$ & $3.527^{\star *}$ \\
\hline
\end{tabular}

${ }^{*} \mathrm{p}<0.05,{ }^{* *} \mathrm{p}<0.01$.

Table 3. Comparison of the level of positive processing differences.

\begin{tabular}{|c|c|c|c|c|c|c|c|}
\hline \multicolumn{2}{|c|}{ Speaking group } & \multicolumn{2}{|c|}{ Writing group } & \multicolumn{4}{|c|}{ Covariance analysis } \\
\hline $\begin{array}{c}\text { Life story I } \\
(M \pm S D) \\
\text { (1) }\end{array}$ & $\begin{array}{c}\text { Life story II } \\
(M \pm S D) \\
\text { (2) }\end{array}$ & $\begin{array}{c}\text { Life story I } \\
(M \pm S D) \\
\text { (3) }\end{array}$ & $\begin{array}{c}\text { Life story II } \\
(M \pm S D) \\
\text { (4) }\end{array}$ & (1)(2) $\mathrm{F}$ & (3) (4) $\mathrm{F}$ & (1)(3) F & (2)(4) $\mathrm{F}$ \\
\hline $3.098 \pm 0.578$ & $4.097 \pm 0.563$ & $3.661 \pm 0.744$ & $4.500 \pm 1.168$ & $17.824^{\star * *}$ & 2.513 & $9.694^{\star *}$ & 1 \\
\hline
\end{tabular}

${ }^{* *} \mathrm{p}<0.01,{ }^{* * *} \mathrm{p}<0.001$. 
results. When there are listeners, the individual experience shows a higher level of language and tends to describe events in more explanatory language. Besides the description of the event itself and self, it also involves more description of the relationship with the surrounding people (Paupathi \& Hoyt, 2009) [17]. There is an inseparable relationship between communion and interpersonal, and individuals tend to have a higher level of communion under the mode of speaking. Therefore, future researchers can continue to explore whether individual interpersonal relationships can be regulated through psychobiography therapy under the mode of speaking.

\subsection{Analysis of the Differences of Positive Processing Level within and between Two-Stage Life Story Groups}

In the comparison of the positive processing level in the group, there was no significant difference before and after the positive processing level in the writing group, but there was a significant improvement in the speaking group. There was no significant difference before and after the positive processing level in the writing group, which may be related to the decrease of the subjects' sense of self-significance. Subjects were asked to write the life story two times, and the second time their sense of self meaning was lower than the first time (Danoff-burg et al., 2010) [18]. According to the observation on the scene of group counseling, in the later stage of writing, the subjects in the writing group did not want to write and were embarrassed to say, while the subjects in the speaking group did not. The positive processing level of the speaking group was significantly improved, which was consistent with the previous research results. Compared with writing, the subjects' positive and adaptive cognitive changes were more under the speaking mode (Murray, 1994) [19]. This could be because both groups at the same time, the narrative group has more content to express and more content to evaluate for positive processing. Future research should consider the influence of this factor and provide more rigorous time control methods.

In the comparison of the difference of the positive processing level between the speaking group and the writing group, the positive processing level of the writing group was higher than that of the speaking group. This result may be because the mode of writing is more in line with the habits of the Chinese people. For many Chinese people, it may be difficult to express their worries and painful experiences orally. It will be easier to change the mode of writing. Through the integration and reconstruction of life stories by writing, individuals can reintegrate those positive and self-actualizing life fragments that may have been neglected before into life stories, thus improving the level of positive processing ( $\mathrm{Wu}$ Jin, 2010) [20]. There is a close relationship between the level of positive processing and the ability of emotion regulation (Cox \& McAdams, 2014) [2], and Individuals tend to have a higher level of positive processing under the writing style, so in the future, researchers can continue to explore whether it is possible to improve the individual's ability of emotion regulation through psychobiographical therapy in the written mode. 


\section{Conclusions}

In the comparison of two-stage life stories, the participants' positive processing level and sense of self-mastery increased, while their sense of status/victory decreased. That is, individuals have a more positive bias in their assessment of the impact of past events on their self-growth, and at the same time, they feel that they are in the process of continuous improvement and increasing awareness of self-control, and have less need to affirm their value through external evaluation.

Different narrative modes have different influences on the life story theme and the positive processing level. Speaking is more conducive to the individual presenting a higher communion level, while writing is more conducive to the individual presenting a higher positive processing level. The future psychological intervention work can reasonably choose the appropriate narrative mode according to different intervention purposes.

\section{Acknowledgements}

The reported research was supported by 2019 "Curriculum Ideology and Politics" education Reform Project of Hangzhou Normal University: The integration of college students' mental health education and ideological and political education under the new situation. The results were presented at the 22nd Chinese academic conference on psychology in Hangzhou/China, October 2019.

\section{Conflicts of Interest}

The authors declare no conflicts of interest regarding the publication of this paper.

\section{References}

[1] Pennebaker, J.W. and Graybeal, A. (2001) Patterns of Natural Language Use: Disclosure, Personality, and Social Integration. Current Directions in Psychological Science, 10, 90-93. https://doi.org/10.1111/1467-8721.00123

[2] Cox, K. and Mcadams, D.P. (2014) Meaning Making during High and Low Point Life Story Episodes Predicts Emotion Regulation Two Years Later: How the Past Informs the Future. Journal of Research in Personality, 50, 66-70. https://doi.org/10.1016/j.jrp.2014.03.004

[3] McCoy, T.P. and Dunlop, W.L. (2016) Contextualizing Narrative Identity: A Consideration of Assessment Settings. Journal of Research in Personality, 65, 16-21. https://doi.org/10.1016/j.jrp.2016.08.006

[4] Grysman, A. and Denney, A. (2017) Gender, Experimenter Gender and Medium of Report Influence the Content of Autobiographical Memory Report. Memory, 25, 132-145. https://doi.org/10.1080/09658211.2015.1133829

[5] Zheng, J.H. and He, C.L. (2015) Psychobiographical Therapy: Theory and Practice. Life Narrative and Psychobiography. (In Chinese)

[6] McLean, K.C., Syed, M., Pasupathi, M., Adler, J.M., Dunlop, W.L., Drustrup, D., McCoy, T.P., et al. (2020) The Empirical Structure of Narrative Identity: The Initial Big Three. Journal of Personality and Social Psychology, 119, 920-944. https://doi.org/10.1037/pspp0000247 
[7] Adler, J.M. (2012) Living into the Story: Agency and Coherence in a Longitudinal Study of Narrative Identity Development and Mental Health over the Course of Psychotherapy. Journal of Personality \& Social Psychology, 102, 367-389. https://doi.org/10.1037/a0025289

[8] McAdams, D.P. (2001) Coding Autobiographical Episodes for Themes of Agency and Communion. Northwestern University, Evanston, 4.

[9] Lyubomirsky, S., Sousa, L. and Dickerhoof, R. (2006) The Costs and Benefits of Writing, Talking, and Thinking about Life's Triumphs and Defeats. Journal of Personality and Social Psychology, 90, 692-708. https://doi.org/10.1037/0022-3514.90.4.692

[10] Habermas, T. and Bluck, S. (2000) Getting a Life: The Emergence of the Life Story in Adolescence. Psychological Bulletin, 126, 748-769.

https://doi.org/10.1037/0033-2909.126.5.748

[11] Lilgendahl, J.P. and Mcadams, D.P. (2011) Constructing Stories of Self-Growth: How Individual Differences in Patterns of Autobiographical Reasoning Relate to Well-Being in Midlife. Journal of Personality, 79, 391-428. https://doi.org/10.1111/j.1467-6494.2010.00688.x

[12] Frattaroli, J. (2006) Experimental Disclosure and Its Moderators: A Meta-Analysis. Psychological Bulletin, 132, 823-865. https://doi.org/10.1037/0033-2909.132.6.823

[13] Roberts, M. (2012) Balint Groups: A Tool for Personal and Professional Resilience. Canadian Family Physician Médecin De Famille Canadien, 58, 245-247.

[14] McAdams, D.P. (2001) The Psychology of Life Stories. Review of General Psychology, 5, 100-122. https://doi.org/10.1037/1089-2680.5.2.100

[15] McAdams and Dan, P. (1996) Personality, Modernity, and the Storied Self: A Contemporary Framework for Studying Persons. Psychological Inquiry, 7, 295-321. https://doi.org/10.1207/s15327965pli0704_1

[16] Klein, K. and Boals, A. (2001) Expressive Writing Can Increase Working Memory Capacity. Journal of Experimental Psychology General, 130, 520-533. https://doi.org/10.1037/0096-3445.130.3.520

[17] Pasupathi, M. and Hoyt, T. (2009) The Development of Narrative Identity in Late Adolescence and Emergent Adulthood: The Continued Importance of Listeners. Developmental Psychology, 45, 558-574. https://doi.org/10.1037/a0014431

[18] Danoff-Burg, S., Mosher, C.E., Seawell, A.H. and Agee, J.D. (2010) Does Narrative Writing Instruction Enhance the Benefits of Expressive Writing? Anxiety Stress \& Coping, 23, 341-352. https://doi.org/10.1080/10615800903191137

[19] Murray, E.J. and Segal, D.L. (1994) Emotional Processing in Vocal and Written Expression of Feelings about Traumatic Experiences. Journal of Traumatic Stress, 7, 391-405. https://doi.org/10.1002/jts.2490070305

[20] Wu, J. (2010) Study on the Role of Narrative Style in Personality Development. Doctoral Dissertation, Nankai University, Nankai. (In Chinese) 